Doi: https://doi.org/10.31578/jebs.v6i1.219

\title{
Unifying Personal Development Through Dance and Movement and Increasing the Level of Bodily Intelligence
}

Florin Vancea*

\begin{abstract}
This paper aims at presenting a study on bodily intelligence, a relatively new term that joins the most established ones such as cognitive intelligence, emotional intelligence or spiritual intelligence. The theoretical basis is supported by Gardner's theory of multiple intelligence as well as more recent neurological and psychological studies on the human body. A form of knowledge is highlighted which, although it is the first to appear in human ontogenesis, has not been much studied and promoted and which opposes rational or iconic knowledge. The present study aims at finding a tool for measuring bodily intelligence and at investigating the dynamics of this intelligence in relation to participating in a unifying personal development program through dance and movement. In this sense we went through two major stages and objectives at the same time: 1 - conducting a unifying personal development program through dance and 2 - conducting a quantitative statistical study to capture the effects of the program on bodily intelligence and its correlation with self-satisfaction related to the physical body. The quantitative (experimental) research was applied with the participation of an experimental group composed of 33 people and a control group composed of 36 people. The results were obtained by pre-test-post-test procedure. The initial testing was held at the beginning of the program and retesting - one day after its completion. The experiment consisted of a UPDDM program lasting 20 hours over three days. The results obtained from the statistical data processing show significant differences between the control group and the experimental group in the bodily intelligence variable confirming the research hypothesis, according to which a UPDDM dance therapy program is a valid method of increasing bodily intelligence.
\end{abstract}

Key words: personal development, dance therapy, bodily intelligence, kinesthetic intelligence.

\section{Introduction}

\subsection{Kinesthetic intelligence and bodily intelligence}

The theory of multiple intelligence developed in 1983 by Dr. Howard Gardner, a professor at Harvard University, presents eight different types of intelligence that cover a wide range of intelligences. The 8 fundamental dimensions of the concept of multiple intelligence, according to Gardner's theory, are: verbal / linguistic, logical-mathematical, spatial, kinesthetic, musical, intrapersonal, interpersonal and naturalistic. He later introduced the existentialist intelligence (Gardner, 2007).

Kinesthetic intelligence takes into account the abilities of expression with the help of the body, very good coordination between the body parts, and solving the problems through physical activities. It is the specific intelligence of athletes, actors, dancers, ballerinas, and surgeons, those who have trades in which the finesse of movements is important. People with a developed kinesthetic intelligence have a very good eye-hand coordination, a great ability to express emotions through movement and are

* Ph. D, University Lecturer, Spiru Haret University, Bucharest, Romania 
talented in sports. Therefore, kinesthetic intelligence involves the expression of the body, the ability to use the whole body or parts of the body to do different activities, to learn or solve problems in everyday life.

The term 'bodily intelligence' (or 'somatic intelligence') is newer and implies something more than the kinesthetic intelligence it encompasses. Bodily intelligence is based not only on the kinesthetic sense, but also on the inner sense. The information we receive from the internal environment, even when it is still, is a source of deep and complex knowledge with which we can make better decisions in life.

Bodily intelligence is a capacity that we have and that involves first of all the attention focused on the body, on the signals coming from the interoceptive sensory system, in order to know the environment and the relationship we have with it. Secondly, it involves a form of continuous dynamic processing of this information through the locomotor kinesthetic system in order to better adapt to the environment. It is the oldest form of intelligence as the somatic experience is the first 'language' of the human being. Knowledge through the body, also called embodied cognition, is opposed to mental knowledge and is the first form of cognition that the human being uses. Before speaking, before assimilating the ability to reason and analyze, which is the attribute of mental knowledge, man relies on bodily sensations and adapts to the environment through movement.

The approaches to 'embodied cognition' and 'enaction' promote the theory that human behavior arises from the realtime interaction between the nervous system and the environment that provides opportunities and information. Enactive is an adjectival term developed by Maturana and Varela (1992) to refer to the third orientation in cognition (neither fundamentally objective, nor fundamentally subjective). This term was introduced to emphasize the idea that cognition is not the representation of a given world by a given mind, but rather the reproduction of a world and a mind based on all the actions that a being has and performs in the world. The term enaction is used to describe a third way of organizing knowledge and one of the forms of interaction with the world. The first definition of enaction was introduced by psychologist Bruner in connection with the structure of the other two paths of knowledge: iconic and symbolic. Active knowledge is knowledge that comes through action and is built on motor skills such as handling objects, cycling or playing a sport. It is more natural than symbolic or iconic (imagistic) knowledge both in terms of the learning process and in the way it is applied in the world. Such knowledge is inherently multimodal because it requires the coordination of the various senses. Symbolic knowledge uses mathematical words or symbols, and iconic knowledge uses images.

The approach of bodily intelligence supported by these studies and theories on embodied cognition and enaction shows that the human body is not only a passive receiver of the impulse of the environment, but also an actor in this environment so that what he experiences is shaped by the way in which he acts.

'Bodily intelligence' as a scientific concept is supported by numerous studies and research. We mention here the studies conducted in 2009 by Alejando Lleras, PhD in Psychology at the University of Illinois and Laura Thomas, PhD in Psychology at Vanderbilt University, on how to solve problems through body movements. The results showed that body movement influences deep thoughts and the ability to solve difficult problems. Lleras and Thomas pointed out that "People are inclined to believe that their minds live in the brain and deal with abstract aspects that have nothing to do with the body...This innovative study is fascinating because it demonstrates how the body is a part of our mind in an overwhelming way. The way it thinks is affected by our body and, in fact, we can use our body to help us think. " (Lleras \& Thomas, as cited in Sisgold, 2016, p.68)

\subsection{Unifying personal development through dance and movement}

Psycho-corporal therapies and unifying personal development groups through dance and movement can be complex and profound methods of therapeutic and personal development interventions, having both healing and psychosomatic 
transformation powers and personality restructuring. This is because the body is the basis of personality, the primary and most condensed way of being in this existence and a faithful memory of all the events that an individual has experienced. Dance and movement are the oldest, best known and most elegant psycho-corporeal reaction to reality. Dance and movement therapy (DMT) is part not only of the category of psycho-corporeal approaches to treatment, but also of expressive-creative therapies, along with music therapy, visual art therapy and drama therapy. It is based on the principle that movements and emotions are in a permanent connection.

But what is most interesting about our study is the relationship that is created between authentic, deep reconnection with the body, awareness and assumption of all sensory and emotional feelings involved in its movement and the dynamics of bodily intelligence and emotional intelligence. What actually happens in these activities is the recovery and reintegration of the body, the general tendency of modern human being to separate from himself and withdraw into the mind (Wilber, 2005). DMT provides a framework in which the participants feel safe to reveal their emotional problems, using movements, images, symbols and metaphors. In a supportive setting, people can externalize their emotions and feelings. Being a creative therapy, it cannot fail: no matter what movement it makes, be it bizarre, aggressive or disturbing, it will be valued and appreciated. Experience shows that subjects feel better doing something about their feelings than just talking about them (Stanton-Jones, 1992).

The unifying personal development program through dance and movement (UPDDM) has been inspired by classical dance and movement therapies, but it is built according to the method specific to the Unifying Experiential Therapy, elaborated by professor lolanda Mitrofan, in Romania. (Mitrofan, 2000, 2004). This UPDDM program was initiated by Mitrofan in 2000 and later developed and implemented by the author of this article. The descriptions and validations of this UPDDM program through studies and scientific research have been made since 2009, by Vancea $(2009,2012,2013,2014)$.

UPDDM is a workshop of intrapersonal, interpersonal and transpersonal development which resorts to music, movement, dance and meditation. UPDDM starts from the fundamental principle of any dance/movement therapy: the mind and the body are profoundly inter-connected, thus, on the one hand, the movements of the body reflect the person's inner state and, on the other hand, the natural process of restructurisation and self-cure is triggered by moving the body in an intuitive nonbinding way. The most important goal of the workshop is the inner unification, body-mind-soul-spirit, by regarding the body as the densest material part of the human being.

UPDDM uses the artistic type of universal languages, mainly those specific to the program: movement, dance, rhythm and music. They are harmoniously completed with visual arts, self-exploring narrative imagery, metaphorical scenario and creative drama-therapeutic improvisation. These preverbal languages are the only ones with access to that extremely profound, mythical and archetypal human level, which contains the key, the solutions to all the problems related to human development.

The study from 2013 demonstrated that UPDDM is a valid method of increasing the emotional intelligence by reconnecting with one's own body and through the inner unification between body, emotion, reason and spirit. And the study from 2014 showed that UPDDM is a valid method of increasing the level of differentiation of self.

\section{Research design and method}

The aim of this research is to capture the dynamics of the levels of bodily intelligence, kinesthetic intelligence and emotional intelligence that are triggered through participation in a unifying personal development program through dance and movement (UPDDM). 


\subsection{Objectives}

1. Development of a 20-hour UPDDM program and its implementation as an experiment.

2. Identification of instruments to measure the levels of the three forms of intelligence and determination of these levels on the study group

3. Determining the correlations that exist between the three forms of intelligence.

\subsection{Work hypotheses}

I.1. Going through a unifying personal development program through dance and movement determines the increase of the level of bodily intelligence.

I.2. There is a positive correlation between the level of bodily intelligence and the level of kinesthetic intelligence.

\subsection{Study group}

The experimental-quantitative research was performed with the participation of an experimental group composed of 33 people and a control group composed of 36 people. The 69 subjects are part of different social and professional categories, students or graduates of psychology aged between 18 and 54 years. In the selection of the two groups, the participants expressed the desire to participate in this research and in addition were ready, in case of the experimental group, to participate in the UPDDM program.

\subsection{The tools used for the quantitative study}

a. A bodily intelligence test, translated and readapted from Suzanne Scurlock-Durana questionnaire (a researcher with 30 years of experience in body work), was used to measure the level of bodily intelligence (Scurlock-Durana, 2017).

b. Kinesthetic intelligence test, taken over and adapted from Gardner's Multiple Intelligence Test. Only the part that measures kinesthetic intelligence was taken to measure the level of kinesthetic intelligence (Psychology Today, 2020).

c. Emotional intelligence test adapted by Roco, M. (2004) after Bar-On and Goleman for measuring the level of emotional intelligence.

The instruments were applied before and after the experiemnt. The initial testing was conducted at the beginning of the program and the retest - one day after its end.

\subsection{The experiment}

The experiment consisted of a 20 -hour unifying personal development program through dance and movement (UPDDM) over a three-day period. UPDDM is a complex program, inspired by DMT, which respects the methodology of Experiential Unification Therapy. The program is a transformative journey that uses music, movement, dance and meditation. UPDDM starts from the basic principle of any dance therapy, that the mind and body are deeply interconnected, so that body movements reflect the inner state of the person and in addition to moving the body in an intuitive and unconstraining manner, in an environmentguided and protected therapy, the natural process of restructuring and self-healing is triggered. This principle is used to achieve the first desideratum of that workshop of inner unification, body-mind-soul-spirit, starting from the body as the densest structure of the man, unification that puts the person back on the ascending path of his / her spiritual evolution in authenticity and naturalness. 
UPDDM uses the witness state as the main transformation tool, and the body metaphor as the main vehicle. The workshops within this program use in their integrative way a series of techniques of restructuring and unpsychic, somatopsychic, interpersonal and transpersonal unification in the new, holistic vision of the Experiential Unification Therapy. The modalities of intervention are based on the transfigurative power of the metaphor, especially the corporal one, of the creative meditation used in group and individually, of the awareness through focused corporal, affective, cognitive and behavioral self-exploration. UPDDM appeals to universal artistic languages, mainly to the specific ones: rhythm, music, dance, movement, harmoniously complemented with modeling, collage, visual arts, self-exploratory narrative imagery, metaphorical scenario, creative therapeutic improvisation. In this way, the immersion in the individual, transgenerational and collective unconscious is much deeper and more revealing, and its connection and re-harmonization with the conscious level is achieved spontaneously.

These 'languages' are the only ones that have access to that extremely deep (preverbal) human level, the mythical, archetypal level that contains the keys, the solutions to all the problems related to human development. The improvisation exercises through movement and dance are harmoniously interspersed in some places with musical improvisations (vocal and with instruments), with graphic and collage type creations that give a deep expressive-creative therapeutic nature.

UPDDM makes extensive use of symbolic and archetypal meanings. In the improvisation phase, the archetypal-symbolic sphere is accessed on two axes: the vertical axis and the horizontal axis. The sky-earth connection is recreated on the vertical axis. On the horizontal axis, the movement of each participant takes place between the pole of isolation, loneliness, self-centering, self-relationship through movements and dance performed individually, sometimes with eyes closed, touching one's body, individual self-expression, etc. and the pole of communion with others through movements and dancing in pairs, in subgroups and then in the whole group.

\section{The results obtained}

Analysis of the dynamics of the levels of the three types of intelligence: bodily, kinesthetic and emotional in the subjects of the experimental group as a result of their participation in the UPDDM program shows insignificant increases of kinesthetic intelligence and emotional intelligence and a significant increase in bodily intelligence. Table 1 shows the mean of the three variables before and after the experiment. In figure 1 a graph with the percentage increases of the three variables before and after the experiment is presented.

Table 1: The mean of the three variables, before and after the experiment

\section{Descriptive Statistics}

\begin{tabular}{|l|r|r|r|r|r|}
\hline & $N$ & Minimum & Maximum & Mean & Std. Deviation \\
\hline Emotional intelligence before & 33 & 25 & 160 & 89.09 & 42.084 \\
Emotional intelligence after & 33 & 45 & 165 & 93.18 & 38.746 \\
Kinesthetic intelligence before & 33 & 23 & 32 & 28.27 & 2.491 \\
Kinesthetic intelligence after & 33 & 26 & 31 & 28.09 & 1.958 \\
Bodily intelligence before & 33 & 11 & 31 & 21.18 & 6.361 \\
Bodily intelligence after & 33 & 11 & 24 & 17.09 & 4.186
\end{tabular}




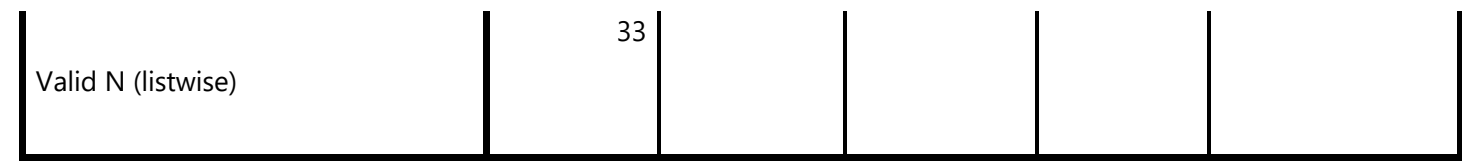

\section{The dynamics of the three types of intelligences \\ -percentage values-}

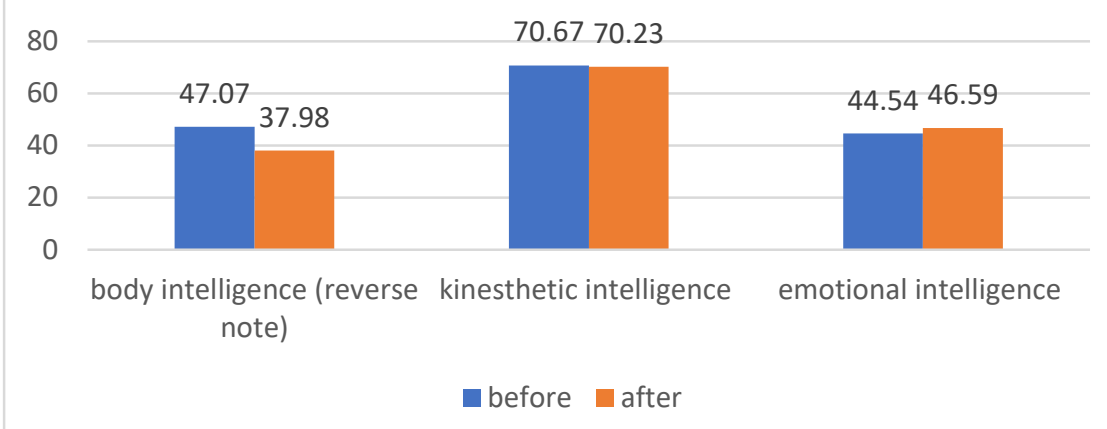

Figure 1: The percentage increases of the three variables before and after the experiment

To verify the hypothesis I.1, two methods of statistical analysis were applied using SPSS software: T-test and ANOVA (see tables 2 and 3$)$.

Table 2: T-test results

\section{Paired Samples Statistics}

\begin{tabular}{|ll|r|r|r|r|}
\hline & \multicolumn{1}{|c|}{ Mean } & \multicolumn{1}{|c|}{$\mathrm{N}$} & \multicolumn{1}{c|}{ Std. Deviation } & \multicolumn{1}{c|}{ Std. Error Mean } \\
\hline \multirow{2}{*}{ Pair 1 } & Bodily intelligence before & 21.18 & 33 & 6.361 & 1.107 \\
& Bodily intelligence after & 17.09 & 33 & 4.186 & .729 \\
\hline
\end{tabular}

Paired Samples Correlations

\begin{tabular}{|c|c|c|c|c|}
\hline & & $\mathrm{N}$ & Correlation & Sig. \\
\hline Pair 1 & Bodily intelligence before $\&$ Bodily intelligence after & 33 & .862 & .000 \\
\hline
\end{tabular}

Paired Samples Test

\begin{tabular}{|c|c|c|c|c|c|c|c|c|}
\hline & \multicolumn{5}{|c|}{ Paired Differences } & \multirow[t]{3}{*}{$\mathrm{t}$} & \multirow[t]{3}{*}{$\mathrm{df}$} & \multirow{3}{*}{$\begin{array}{l}\text { Sig. (2- } \\
\text { tailed) }\end{array}$} \\
\hline & \multirow[t]{2}{*}{ Mean } & \multirow[t]{2}{*}{$\begin{array}{c}\text { Std. } \\
\text { Deviation }\end{array}$} & \multirow[t]{2}{*}{$\begin{array}{l}\text { Std. } \\
\text { Error } \\
\text { Mean }\end{array}$} & \multicolumn{2}{|c|}{$\begin{array}{l}\text { 95\% Confidence } \\
\text { Interval of the } \\
\text { Difference }\end{array}$} & & & \\
\hline & & & & Lower & Upper & & & \\
\hline $\begin{array}{l}\text { Pai Bodily intelligence before - Bodily } \\
\text { r } 1 \text { intelligence after }\end{array}$ & 4.091 & 3.476 & .605 & 2.858 & 5.324 & 6.760 & 32 & .000 \\
\hline
\end{tabular}


Table 3: ANOVA results

Descriptives: Bodily intelligence after

\begin{tabular}{|c|c|c|c|c|c|c|c|c|}
\hline & \multirow[t]{2}{*}{$\mathrm{N}$} & \multirow[t]{2}{*}{ Mean } & \multirow[t]{2}{*}{ Std. Deviation } & \multirow[t]{2}{*}{ Std. Error } & \multicolumn{2}{|c|}{$\begin{array}{c}\text { 95\% Confidence Interval for } \\
\text { Mean }\end{array}$} & \multirow[t]{2}{*}{ Minimum } & \multirow[t]{2}{*}{ Maximum } \\
\hline & & & & & Lower Bound & Upper Bound & & \\
\hline experimental & 33 & 17.09 & 4.186 & .729 & 15.61 & 18.58 & 11 & 24 \\
\hline control & 36 & 21.25 & 4.831 & .805 & 19.62 & 22.88 & 12 & 32 \\
\hline Total & 69 & 19.26 & 4.964 & .598 & 18.07 & 20.45 & 11 & 32 \\
\hline
\end{tabular}

\section{Test of Homogeneity of Variances}

Bodily intelligence after

\begin{tabular}{|l|l|l|l|}
\hline Levene Statistic & df1 & df2 & Sig. \\
\hline .100 & 1 & 67 & .753 \\
\hline
\end{tabular}

ANOVA

Bodily intelligence after

\begin{tabular}{|l|r|r|r|r|r|}
\hline & Sum of Squares & \multicolumn{1}{|c|}{$\mathrm{df}$} & Mean Square & F & \multicolumn{1}{|c|}{ Sig. } \\
\hline Between Groups & 297.827 & 1 & 297.827 & 14.486 & .000 \\
Within Groups & 1377.477 & 67 & 20.559 & & \\
Total & 1675.304 & 68 & & & \\
\hline
\end{tabular}

Buased on the obtained statistical results:

a. The $t$ test for paired samples shows statistically significant increases only in the bodily intelligence variable. The average for the values of bodily intelligence in the subjects from the experimental group after participating in the UPDDM program is significantly higher $(t=6.760, D F=32$, two-tailed $p=0.000<0.01)$.

b. The unifactorial analysis of variance - ANOVA method, with which we can compare the values of the experimental group with the values of the control group, shows that the effect of the UPDDM program on the bodily intelligence variable was significant $(F=14,486$, two-tailed $p=0.000<0.01)$. The Levene Test was used.

Thus hypothesis I.1. has been confirmed.

To verify the hypothesis I.2. correlational analysis was applied using SPSS software. The main correlations are presented in Table 2.

It can be seen that the level of bodily intelligence correlates positively with the level of kinesthetic intelligence: $r=$ 0.308 at the significance threshold $p=0.010$ (in bodily intelligence the grades are reversed). Hypothesis I.2. has, therefore, been confirmed. 
Table 4: The main correlations

\begin{tabular}{|c|c|c|c|c|c|c|}
\hline Correlations & & age & gender & $\begin{array}{c}\text { Emotional } \\
\text { intelligence }\end{array}$ & $\begin{array}{l}\text { Kinesthetic } \\
\text { intelligence }\end{array}$ & $\begin{array}{c}\text { Bodily } \\
\text { intelligence }\end{array}$ \\
\hline \multirow{4}{*}{ Age } & $\begin{array}{l}\text { Pearson } \\
\text { Correlation }\end{array}$ & 1 & $.330^{\star \star}$ & $-.243^{*}$ & .136 & $-.411^{\star \star}$ \\
\hline & Sig. (2-tailed) & & .006 & .044 & .264 & .000 \\
\hline & $\mathrm{N}$ & 69 & 69 & 69 & 69 & 69 \\
\hline & $\begin{array}{l}\text { Pearson } \\
\text { Correlation }\end{array}$ & $.330 * *$ & 1 & -.145 & -.140 & .040 \\
\hline \multirow[t]{3}{*}{ Gender } & Sig. (2-tailed) & .006 & & .234 & .251 & .746 \\
\hline & $\mathrm{N}$ & 69 & 69 & 69 & 69 & 69 \\
\hline & $\begin{array}{l}\text { Pearson } \\
\text { Correlation }\end{array}$ & $-.243^{*}$ & -.145 & 1 & -.035 & -.215 \\
\hline \multirow[t]{3}{*}{ Emotional intelligence } & Sig. (2-tailed) & .044 & .234 & & .777 & .076 \\
\hline & $\mathrm{N}$ & 69 & 69 & 69 & 69 & 69 \\
\hline & $\begin{array}{l}\text { Pearson } \\
\text { Correlation }\end{array}$ & .136 & -.140 & -.035 & 1 & $-.308^{*}$ \\
\hline \multirow[t]{3}{*}{ Kinesthetic intelligence } & Sig. (2-tailed) & .264 & .251 & .777 & & .010 \\
\hline & $\mathrm{N}$ & 69 & 69 & 69 & 69 & 69 \\
\hline & $\begin{array}{l}\text { Pearson } \\
\text { Correlation }\end{array}$ & $-.411^{* *}$ & .040 & -.215 & $-.308^{*}$ & 1 \\
\hline \multirow[t]{2}{*}{ Bodily intelligence } & Sig. (2-tailed) & .000 & .746 & .076 & .010 & \\
\hline & $\mathrm{N}$ & 69 & 69 & 69 & 69 & 69 \\
\hline
\end{tabular}

**. Correlation is significant at the 0.01 level (2-tailed).

*. Correlation is significant at the 0.05 level (2-tailed).

This significant, but not very high correlation is very important. It can validate the intersection between the two forms of intelligence: the kinesthetic and the bodily. These two adaptive capacities, as forms of intelligence, overlap on a certain level of the human being, because in both it is about what we live and experience in the body. On the other hand, the correlation between them is not very high, which highlights and confirms that bodily intelligence and kinesthetic intelligence are distinct, as described in the theoretical part of this study.

The correlative analysis also highlights a significant correlation between the level of bodily intelligence and the age of the subjects in the study group. There is a strong negative correlation $r=-0.411$ at the significance threshold $p=0.000$ (the item in the questionnaire is a reverse one, which means that, in fact, the correlation is positive). It indicates that, in the case of the study group used, older subjects have higher levels levels of bodily intelligence than younger ones. This is an aspect that can be considered for future studies.

\section{Discussion}

This paper includes a study on the effectiveness of a unifying personal development program through dance and movement (UPDDM), conducted over 20 hours, in terms of increasing bodily intelligence. 
Previous studies (Vancea, 2012, 2013, 2014) based on the UPDDM program comprising three modules (20 hours each) have demonstrated the effectiveness of this program on the following aspects:

- Increased level of emotional intelligence;

- Increased level of self-differentiation;

- Decreased tendency to emotional separation;

- Decreased tendency to blend;

- Decreased anxiety level;

- Decreased depressive tendency;

- Increased level of self-satisfaction.

As a continuation of the previous research, the present study, based on the same program, but for shorter time (a 20hour module) shows its effectiveness on bodily intelligence. 20 hours of this program were enough for a significant increase in bodily intelligence. The techniques and methods used in this program awaken and enhance bodily intelligence very easily. Unlike bodily intelligence, kinesthetic intelligence does not increase after 20 hours of dancing and movement. Emotional intelligence increases very little and at statistically insignificant level after a 20-hour module, but it can increase significantly after three 20hour modules, an aspect highlighted in a previous study (Vancea, 2013)

Movement and dance, involving the body and the capacities of mobilization and nonverbal interaction, integrated in a personal development group, are expected to lead to better contact with the body and emotions. Mobilizing the body, focusing on bodily sensations and associated emotions allow not only a better activation and awareness of one's emotions and nonverbal expression, but also the possibility of adaptive processing of all this information in a deeper, authentic, direct and natural way, involving the body. However, the present research demonstrates that such an adaptive capacity, which is bodily intelligence, can be quite easily increased and in a relatively short time.

It is also worth discussing the practical validity of this tool for measuring bodily intelligence, which is the adaptation of the Scurlock-Durana (2017) questionnaire. One can observe the sensitivity of this questionnaire to the dynamics of personal changes in the field of psycho-corporeal research work. Therefore, we can consider in the future the use of this instrument to measure the effects of psycho-corporeal interventions.

\section{Conclusions}

We can say that unifying personal development through dance and movement (UPDDM) can be considered a valid and quick method of increasing bodily intelligence which can lead to an inner unification between body, emotion, reason and spirit.

Even though the size of the study group was not too large, the statistical analysis using the SPSS software and the $t$ Test and ANOVA method show a significant increase in bodily intelligence following the participation of subjects in the experimental group in the UPDDM 20 hours program. 


\section{References}

Gardner, H. (2007). Inteligențe multiple. Noi orizonturi pentru teorie și practică [Multiple intelligences. New horizons for theory and practice]. Bucharest: Sigma Publishing House.

Goleman, D. (2001). Inteligenţa emoţională. (Emotional intelligences). Bucharest: Curtea veche Publishing House.

Maturana, H.R. \& Varela, F.J. (1992). Afterword. The Tree of Knowledge: The Biological Roots of Human Understanding (Revised ed.). Boston, MA: Shambhala Publications Inc.

Mitrofan, I. (2004). Terapia Unificării [Unifying Therapy]. Bucharest: SPER Publishing House.

Mitrofan, I. (2000). Orientarea experiențială în psihoterapie [Experiential orientation in psychotherapy. Personal, interpersonal and transpersonal development]. Bucharest: SPER Publishing House.

Psychology Today. (2020). Multiple intelligences and learning style test. Retrieved May 10, 2020 from https://www.psychologytoday.com/us/tests/iq/multiple-intelligences-learning-style-test

Roco, M. (2004). Creativitate şi inteligenţă emoţională, (Creativity and emotional intelligences). Iași: Polirom Publishing House.

Scurlock-Durana, S. (2017). Reclaiming Your Body: Healing from Trauma and Awakening to Your Body's Wisdom. Novato, CA: New World Library

Test your body intelligence. Retreived May 10, 2020 from https://spiritualityhealth.com/articles/2017/09/18/quiz-test-your-bodyintelligence

Sisgold, S. (2016). Inteligența Corporală [Bodily intelligences]. Bucharest: Niculescu Publishing House.

Stanton-Jones, K. (1992). An Introduction to Dance Movement Therapy in Psychiatry. London, New York: Routledge.

Vancea, F. (2009). Introducere în terapia prin dans [Introduction to dance therapy]. Sibiu: Psihomedia Publishing House.

Vancea, F. (2012). Valențele optimizatoare ale unui modul de dezvoltare personală unificatoare cu suport corporal [The optimizing valences of a unifying personal development module with body support]. In Dumitrache, S. \& Mitrofan, I. Din culisele psihoterapiei experiențiale unificatoare - studii de caz și cercetări aplicative [Behind the scenes of unifying experiential psychotherapy - case studies and applied research]. (pp. 21-56). Bucharest: SPER Publishing House.

Vancea, F. (2013). Unifying personal development through dance, movement and the increase of the emotional intelligence level. Journal of Experiential Psychotherapy, vol. 16, no. 3(63), 3-9.

Vancea, F. (2014). Dans mouvement therapy and the increase of the differentiation level of the self. The Proceedings of the International Conference Globalization, Intercultural Dialogue and National Identity, 29-30 May 2014, Târgu-Mureş, Volum 1, Section: Psyhology and Sociology, pp. 83-89.

Wilber, K. (2005). Fără granițe. [No borders]. Bucharest: Elena Francisc Publishing. 